\title{
RECENZJE
}

http://dx.doi.org/10.15633/sts.3546

Studia Sandomierskie

$26(2019)$

\section{Lars Q. English, There Is No Theory of Everything. A Physics Perspective on Emergence, Springer 2017, ss. 224 (eBook)}

The book, authored by Lars Q. English, discusses physics dealing with the nonlinear dynamics of complex systems and issues in the philosophy of science. $\mathrm{He}$ currently works at Dickinson College in Carlisle, Pennsylvania ${ }^{1}$. This is a popular science publication and its content reflects the order of the author's interests.

In the introduction, Lars Q. English presents the main purpose of the book. First of all, he wants to show how the discoveries of modern physics change our thinking about emergence. He refers to certain nuances associated with emergence, and at the same time attempts to define the framework for the emergence process. The researcher states that the book is not anti-reductionist, although it shows the practical and fundamental limitations of the reductionist strategy of "divide and rule." Therefore, the author should not be treated as a supporter of strong ontological emergence or strong emergentism ${ }^{2}$.

The author begins the first chapter ("First meetings") with the history of the discovery of the Higgs particle, which aroused widespread curiosity and stimulated the collective imagination thanks to the created mythical circumstances. This particle was even called the "God particle". Its discovery finally clarified the problem of the origin of mass. However, discovering the Higgs particle changed nothing in the physics of condensed matter. Nothing in this field was even subjected to revision or reinterpretation. Elementary particle physics does not have the broader impact on science that is expected from it. English emphasizes that great breakthroughs in physics occurred as a result of discoveries that seemingly unrelated phenomena in time turned out to be different sides of the same coin. If reductionism were to be understood as an integration of knowledge, then all scientists would be reductionists. Unfortunately, reductionism, described by his supporters, is understood differently. It is the view according to which the novelties appearing at higher levels of the organization of matter can be explained by referring to the properties of the components and the rules that govern them in isolation. An example of the impact the discovery

1 https://www.larsenglish.com/cv [accessed: Oct. 15, 2019].

2 See: A. Stephan, Varieties of Emergentism, "Evolution and Cognition" 5 (1999), nr 1, p. 49-59. 
of the Higgs particle had on the physics of condensed matter indicates a significant problem with the reductionist program. As mentioned in the title, emergence opposes such a reductionist approach. At the next levels of organization and complexity we are dealing with the emergence of new irreducible behaviors. The whole is more than the sum of its parts, and there is a reciprocal relationship between the whole and the parts. It is also the structure, not just parts, that affect the behavior and properties of the system. As an example isomers that have different geometrical configurations of the same set of atoms, e.g. isomer of propanol and methoxyethane. Other examples are the mind-body relationship, or the issue of human behavior in companies with a hierarchical structure. The author emphasizes that the essence of emergence can be captured only at the level commensurate with the description. Emergence allows sciences to maintain relative autonomy without denying their connection. However, it does not allow for the creation of the ultimate unified theory of language and description.

In chapter two ("Entering the microcosm"), English deals with the subject of quantum mechanics, which plays a great role in the discussion of reductionism-emergentism. Namely, reductionists in the subatomic world see the final answers about the universe in all its aspects of existence. The notion of an elementary particle is important in the debate between reductionism and emergentism. In reductionism, the real causal power is possessed by objects at the lowest level, i.e. elementary particles. However, it turns out that at the lowest level we are dealing with indeterminacy and potential, with contextual properties depending on the conditions of the experiment. The case is similar with quantum field theory. The particles are interpreted as discrete excitations of the respective field, so they are relational. Therefore, it is not true, as is assumed in reductionism, that relationality and configurability appear only in the case of objects at a higher level. This also occurs at the lowest level. It is also worth looking at a tangled pair of particles, which the author considers an emergent phenomenon. Individual particles at level one form a tangled state that can be considered level two. Properties and processes at level two cannot be reduced to a lower level, since the individual properties of these particles have already disappeared. "Ghost Action" is an example showing that the whole replaced the parts from which it was made.

Chapter Three ("Aggregation of Particles") begins with a short story. However, this isn't significant in the case of atomic objects. Absorption and spontaneous emission of a photon by an atom are like two sides of the same coin. It is different in the case of the large-scale world. We easily recognize in a film when actors imitate the movements of going back in time. We intuitively know that something is wrong. There is a symmetry between the reversibility of the cosmos and the irreversibility of the microcosm. This symmetry cannot be explained from a reductionist point of view, when macrocosm objects consist only of microcosm objects. In this chapter English also refers to Boltzmann's thought experiment of pouring salt crystals into a container containing peppercorns. In doing so we obtain two visible layers: white 
salt and dark pepper. When we start shaking the box, these layers will mix. Further shaking will never allow us to return to the version with two completely separated layers. If we block all peppercorns and salt crystals, except for one crystal, and start shaking the whole thing, we will discover the trajectory of this crystal and we will be able to recreate the path, but then we will lose sight of the whole characterized by a lack of order. When we consider different concepts of time, including the one described by Einstein, when matter affects time, we can conclude that the direction of time is an emergent property dependent on a set of molecules. Then the author gives examples of objects whose macroscopic properties we are not able to discover by dealing with the components of these objects in isolation. As an example, he mentions diamonds and carbon, which have the same components, but a different structure on which their different properties depend. As another example he gives water. Based on one molecule it is not possible to determine all water levels. Another example is the transitions between states of helium-3 or Cooper pairs. The analyzed exemplifications allowed the author to draw the conclusion that an important characteristic feature of emergence is redefining part of the whole from the perspective of the newly formed microstate.

The fourth chapter ("When Matter Reorganizes Itself") is based on an experiment with sulfur hexafluoride (FS6). By putting FS6 it into the container, half liquid and half gas is obtained. Under the conditions of appropriate pressure and at an elevated temperature, the substance FS6 turns completely black for a moment, and then the line separating its liquid and gaseous state disappears. At this time, it is impossible to determine the physical state of FS6. The author draws attention to the dependence of such a phenomenon on the ratio of critical exponents, whose quotient is often 0.33 (e.g. liquid / gas SF6 = 0.33). They are determined experimentally, as the so-called average field theory, where the averaged interactions between particles are emphasized. It allows separating the phases arising from the result of feedback, which are modifications or continuations of the previous phase from completely new - emergent phases. The average field theory, including Wilson's renormalization procedure, allows a better understanding of emergence. When passing through a critical point, there is a change in the physical laws of each phase. Critical point properties allow the clear determination of the physical laws for macroscopic phases. Interestingly, the physical laws of a given phase are also unpredictable despite the knowledge of the physical laws of the resulting phase. The feature of universality is also revealed here. Liquids, ferromagnetics and superconductors have the same critical exponents. English regards renormalization as one of the most important weapons of the emergentist against reductionists. It excludes macroscopic phases from the range of microscopic laws. Another example, similar to the discussed FS6, is also the Hall effect, which is also considered a very strong example of top-down causality.

In chapter five ("Beyond Linear Approximation"), the author moves from linear systems, which physicists have focused on for a long time, to chaos theory. $\mathrm{He}$ mentions the study of Konrad Lorenz, a pioneer of chaos theory. He also gives his 
favorite example, which are two connected pendulums. From a dynamic point of view, the whole of this system is more than the sum of its parts. The coupling makes chaotic dynamics visible, which cannot be achieved by the parts of the pendulum in isolation. Chaos theory indicates that as systems become more complex, strict causality becomes increasingly difficult to determine, and yet, instead of chaos new types of non-linear order arise spontaneously. He also recalls the research of Henri Bénard and John William Strutt (Lord Rayleigh) on liquid. The Rayleigh-Benard convection is a good example of the top-down control characteristic of emergence. The movement of individual molecules is determined by the macroscopic laws of fluid dynamics. The role of pressure, density, volume, temperature and other thermodynamic properties is important here, not quantum mechanics. Another phenomenon interesting from the point of view of emergence is the spontaneous synchronization occurring in biological systems, which is decentralized. The author refers to the research of Arthur Winfree, who was engaged in the mathematical modeling of biological phenomena and tried to meet the criteria for synchronization. However, it was only the Japanese physicist Yoshiki Kuramoto who succeeded in building a mathematical model describing synchronization in a general way. An example is the cluster of flying birds. Both in the case of convection and spontaneous synchronization we have to deal with feedback. However, in the case of the convection discussed earlier, we are dealing with a structural approach rather than an agent approach. The macro-scale phenomenon limits the micro-scale phenomena. In the case of a flock of birds, they operate on the basis of simple rules, i.e. adapt your movement to your immediate neighbors, keep the right speed. The defensive movement of the flock depends, however, on the space-time position in the flock. So here we have two types of emergence with top-down impacts of varying degrees. Micro-behaviors are formed by macro-layers that affect micro-behavior.

Chapter six ("The Emergence of Effective Theories") provides an analysis of the cognitive processes at the neural level. English begins with a reductionist approach. He considers an effective neuron model indicating that it raises many questions, e.g. regarding the operation of synapse functioning. According to the reductionists, in order to find solutions to the problems of research you have to go down a level. The author describes the theory of ion concentration and ion channels. However, even this does not fully explain certain things, so one should focus on a single ion channel and refer even deeper to quantum chemistry. In this way we get interesting information about the operation of individual components, but they do not relate to the original problem. In fact, we've only moved away from the original problem - how the cognitive process works. In the process one should leave these microscopic details and come back to the more general level, the way neurobiologists do in creating models. An example of such a model is the Hodgkin-Huxley impulse propagation model from 1952, which is relevant to this day, and was developed at a time when details about ion channels were unknown. This model refers to many biological phenomena and is independent of micro details. Neuroscientists are aware that in order 
to understand certain activities one has to deal with clusters of neurons, thereby performing the abstraction process. There is abstraction in each effective layer, a certain simplification. It is impossible to explain, for example, synchronization in a crowd by examining the individual neurons of all people in it. A better strategy is to create effective theories responsible for specific phenomenological layers. According to English, the belief in the possibility of constructing the final theory is associated with mathematical models. Because models created in various sciences use mathematics, hence it is mistakenly assumed that eventually all will unify, while this mathematization only emphasizes the quantitative side of the model.

Chapter seven ("Social Emergency") begins with English's original experiment, which involved using the Mathematics program for his own Facebook account to analyze his social networks. The resulting structure reflected the real aspects of his social life, and thus influenced the operation of his own elements. This effect is also seen in sociology, in which it is difficult to apply a reductionist approach. The influence of people on society is recognized, but also the influence of society on people. There is a feedback mechanism here. The book by Dave Elder-Vaas, to which he refers, well presents the mechanisms of feedback between the social structure and the individual, emphasizing normative groups. The author gives Korea, which until 1945 was a country with a common language and culture, as an example of feedback, which turned out to have dramatic consequences. After this year, Korea broke up into two countries, one of which was influenced by the democratic US and the other by communist China. Currently, the two countries differ drastically. These differences were caused by different organizational principles of government and trade, not by ethnic or genetic issues. Korean history appears to be an ideal historical experiment for sociologists. In addition, English addresses the issue of social feedback awareness. In multiracial American society, six-month-old children already identify with their race. They distinguish between ethnicity between three and five years. At the age of five, they are aware of social prejudices. Recognizing this difference, however, it did not translate into action. It was only at the age of three that they gave a deeper meaning to this difference, combining them with ubiquitous stereotypes. As we grow, we become aware of stereotypes and stop being subject to them to some extent, but we are still influenced by the opinions of society. Of course, there are individuals who manage to break free from this feedback. The examples given show that the phenomena present in the world lie between reductionism (skipping layers or stressing the lowest) and strong emergence (the layers are completely separate). This delicate feedback that occurs between layers is the underlying reason (is the heart) of emergence.

In the last chapter ("Extended Lessons"), the author points out that the reduction approach to science favors some disciplines and the scientists involved in them, and thus neglects others. It forces certain assessment schemes and creates divisions. The emergent approach emphasizes the interdisciplinary nature of science, emphasizes the egalitarianism of scientific disciplines and cooperation between scientists. This is an approach that reflects scientific reality. Meteorology needs, among other things, 
information technology, geography, and oceanography. Astronomy needs, among other things, geology, nuclear physics and quantum statistics. In science there is also a place for religion. Science and religion do not overlap. They concern two different layers of the person. They can coexist without contradiction. Contrary to reductionism, emergence does not deny the existence of free will, and thus subjective decisions and faith. Religious experience has a psychological basis, but the best experience is described in religious language. Like psychology, it resists biology, but transcends it and uses its own language. In the case of religion, there is also feedback: living faith implies religious experience, and it involves living faith. New emergent religious phenomena arise from this: one looks differently at the outside world and new behavioral patterns appear.

The book presented by English, although published in 2018, includes in its bibliography publications from 2014. Despite the lack of use of the latest literature by the author, it is worth recommending this book to students and graduates of science. This is another book about the phenomenon of emergence, which combines its own field of research with philosophical reflection. The main advantage of emergent phenomena are examples taken from condensed matter physics.

\section{Summary}

Lars Q. English's book consists of an introduction, eight chapters and a short ending. The author shows how the latest discoveries of physics are changing thinking about the world, approving the occurrence of emergence. As a physicist himself, he combined the results obtained in physics with philosophical reflection, hence this book is worth recommending to students and graduates of science with philosophical tendencies.

Key words: emergence, reductionism, anti-reductionism, philosophy of physics

\section{Streszczenie}

Książka Larsa Q. Englisha składa się ze wstępu, ośmiu rozdziałów i krótkiego zakończenia. Autor ukazuje w niej jak najnowsze odkrycia fizyki zmieniają myślenie o świecie, aprobując zachodzenie emergencji. Sam będąc fizykiem, połączył wyniki otrzymywane w ramach fizyki z refleksją filozoficzną, stąd książkę tę warto polecić studentom i absolwentom kierunków ścisłych posiadających zapędy filozoficzne.

Słowa klucze: emergencja, redukcjonizm, antyredukcjonizm, filozofia fizyki 